\title{
Formas de nomear ruas de Campo Grande: o que revela a toponímia do bairro Novos Estados
}

DOl: http://dx.doi.org/10.21165/el.v48i1.2339

\author{
Janaina Domingues Verão das Neves ${ }^{1}$
}

\section{Resumo}

Este artigo tem como objetivo discutir tendências da toponímia urbana do bairro Novos Estados, um dos onze bairros que compõem a região urbana do Prosa, Campo Grande - Mato Grosso do Sul (MS). É também objetivo desta proposta analisar um recorte da toponímia urbana selecionada, considerando a classificação dos topônimos, segundo a motivação semântica (DICK, 1990a); a estrutura formal dos nomes de logradouros catalogados e as línguas de origem dos designativos. A análise evidenciou os seguintes resultados: i) quanto à motivação, prevalecem os topônimos de natureza antropocultural, particularmente os que designam nomes de pessoas, os antropotopônimos, e, em segundo lugar em número de ocorrências, os nomes transplantados de outras localidades (municípios e distritos de estados brasileiros), os corotopônimos; ii) quanto à estrutura morfológica, sobressaem os topônimos de base simples e, iii) quanto à língua de origem, a portuguesa prevalece, seguida de línguas indígenas e de outras línguas (latim, francês, espanhol, árabe, grego, etc.)

Palavras-chave: toponímia urbana; Campo Grande; nomes de ruas; prosa; Novos Estados.

1 Universidade Federal de Mato Grosso do Sul (UFMS), Campo Grande, Mato Grosso do Sul, Brasil; janaina.verao@gmail.com ; https://orcid.org/0000-0002-4862-7764 


\section{Formas de nombrar calles de Campo Grande: lo que revela la toponimia del barrio Nuevos Estados}

\section{Resumen}

El objetivo primario del artículo es discutir tendencias de la toponimia urbana del barrio Nuevos Estados, uno de los once barrios que componen la región urbana del Prosa, Campo Grande - MS. Es también un objetivo de la propuesta analizar el recorte de la toponimia seleccionada considerando la estructura formal de los nombres de las calles catalogados; las lenguas de origen de los topónimos y la clasificación de los topónimos de acuerdo con la motivación semántica (DICK, 1990a). El análisis evidenció los siguientes resultados: i) en relación con la motivación, prevalecen los topónimos de naturaleza antropocultural, en especial los que designan nombres de personas, los antropotopónimos, y en segundo lugar en número de ocurrencias, los nombres referentes a las otras localidades (municipios y distritos de estados brasileños), los corotopónimos; ii) cuanto a la estructura morfológica, predominan los topónimos de base simple; iii) cuanto a la lengua de origen, la portuguesa prevalece, seguida de lenguas indígenas y otras (latín, francés, español, árabe, griego, etc.).

Palabras clave: toponimia urbana; Campo Grande; nombres de calles; prosa; Nuevos Estados.

\section{Introdução}

O ato de nomear os espaços decorre da necessidade do homem de marcar o território, de imprimir a sua marca no lugar que ocupa, o que se acentua com a expansão dos núcleos humanos em territórios delimitados, exigindo a identificação das terras à medida que são habitadas. A disciplina linguística que se ocupa do estudo dos nomes próprios de lugares é a Toponímia, ramo da Onomástica que, por meio da análise linguística e motivacional dos nomes atribuídos aos lugares de uma determinada região, favorece a recuperação de aspectos históricos das transformações dos nomes de lugares, mudanças relacionadas às migrações e colonização, além de desvelar fatores ligados a crenças, história e cultura de um povo.

Este trabalho, recorte da pesquisa em andamento intitulada "A toponímia urbana da cidade de Campo Grande: um estudo etnolinguístico dos nomes das ruas da região do Prosa", projeto de dissertação de Mestrado, vinculada ao Programa de Pós-graduação Estudos de Linguagens e ao Projeto Atlas Toponímico do Estado de Mato Grosso do Sul (ATEMS), tem por objetivo discutir tendências da toponímia urbana do bairro Novos Estados, um dos onze bairros que compõem a região urbana do Prosa, Campo Grande MS. 
A região pesquisada abriga um total de 21 parcelamentos que reúnem 236 topônimos que nomeiam os logradouros pertencentes ao bairro Novos Estados. Esses dados foram extraídos de mapas oficiais do bairro, disponíveis para download no site oficial da Prefeitura Municipal de Campo Grande, Secretaria Municipal do Meio Ambiente e Gestão Urbana - SEMADUR. É objetivo deste artigo, também, analisar o recorte da toponímia urbana selecionada, considerando, a motivação semântica que impulsionou o denominador ao formalizar os nomes das ruas (DICK, 1990a); a estrutura formal dos nomes de logradouros catalogados e as línguas de origem dos topônimos, além de apontar possíveis relações entre os topônimos e as características do bairro Novos Estados, com destaque para a relação entre toponímia, meio ambiente físico e social.

Para tanto, tem-se como referência de base a orientação teórica da Onomástica, mais especificamente da Toponímia, em especial, os pressupostos teórico-metodológicos de Dick (1990a; 1990b; 1997; 1999). Complementam a referência teórica fundamentos da Lexicologia, da Morfologia e da Semântica.

\section{Fundamentação teórica}

O estudo do léxico de uma língua natural possibilita o resgate de aspectos sociolinguísticos e culturais intrínsecos à memória de uma comunidade. Segundo Biderman (2001, p.157), "a nomeação da realidade pode ser considerada como a etapa primeira do nosso percurso científico no conhecimento do universo". Pode-se, pois, conceber o léxico como o nível da língua que melhor evidencia a forma como um dado grupo de usuários enxerga, apreende e representa a realidade na qual está inserido.

Os estudos toponímicos, respaldados pela Linguística, também podem fornecer pistas que favorecem a recuperação de fatos históricos, características linguísticas, marcas de migração e etnológicas da região pesquisada. Isso porque "a toponímia reflete de perto a vivência do homem enquanto entidade individual e enquanto membro do grupo que o acolhe" (DICK, 1990a, p. 119).

Ainda, de acordo com Dick (1990a, p.119), toponimista brasileira,

[...] a Toponímia reserva-se o direito de se apresentar como a crônica de uma comunidade, gravando o presente para o conhecimento das gerações futuras. Assim é que os elementos mais diferenciadores da mentalidade do homem, em sua época e em seu tempo, em face das condições ambientais de vida, que condicionam a sua percepção do mundo, estão representados nos nomes de lugares, senão todos, pelo menos os mais flagrantes. 
A Toponímia configura-se também como disciplina de caráter interdisciplinar, que estabelece diálogo com outras áreas do conhecimento, tais como a História, a Antropologia, a Geografia, dentre outras. Essa afırmação justifica a natureza de seu objeto de estudo, o topônimo. Segundo Aguilera (1999, p. 125),

O topônimo é um produto cultural que tem vida e, tal como o homem, desenvolve-se e dinamiza-se, além de se constituir num bem patrimonial de qualquer país, pois é por meio dos designativos de lugares que uma nação obtém uma personalidade geográfica própria e se particulariza em relação aos demais países, construindose numa fonte inesgotável para o acervo científico.

Assim, como verdadeiros testemunhos históricos de fatos e ocorrências registrados nos mais diversos momentos da vida de uma população, os topônimos veiculam em si um valor para além do ato da nomeação propriamente dito. Nesta perspectiva, adentramos no campo da função denominativa na Toponímia. Esta pode se apresentar em dois planos, ora se apresenta "essencialmente motivada", cujas razões motivadoras se dispõem em planos genéricos, um objetivo ou extrínseco, entendido como uma projeção de circunstâncias exteriores e/ou ambientais refletidas no topônimo, e outro subjetivo ou intrínseco, exprimindo os próprios desígnios do indivíduo ou a sua maneira de perceber e sentir o local denominado, e ora se apresenta "impulsionada por fatores de diferentes conteúdos semânticos que poderão conduzir à localização de áreas toponímicas, correspondentes ou não às respectivas áreas geográfico-culturais" (DICK, 1990b, p. 22).

Outra questão a ser considerada no estudo dos nomes próprios de lugares é a identificação dos signos toponímicos. Ao tratar dessa temática, Dick (1990b, p. 35) esclarece que "apenas o emprego dos signos é que se torna especial nas ciências onomasiológicas; ou, em outras palavras, a função significativa dos mesmos é que se diferencia quando a toponímia os transforma em seu objeto de estudo". Isso porque

\footnotetext{
O topônimo não é algo estranho ou alheio ao contexto histórico político da comunidade. Sua carga significativa guarda estreita ligação com o solo, o clima, a vegetação abundante ou pobre e as próprias feições culturais de uma região em suas diversas manifestações de vida. (DICK, 1990a, p. 47).
}

No que diz respeito à estrutura do topônimo, Dick (1990a, p. 13) identifica os topônimos de estrutura simples, formados por apenas um elemento, como em rua Sergipe, e de estrutura composta, ou seja, "aquele que se apresenta com mais de um elemento formador, de origens diversas entre si, do ponto de vista do conteúdo, gerando, por isso, às vezes, formações inusitadas que, talvez, apenas a história local poderá elucidar convenientemente", como em avenida Mato Grosso. Há também topônimos compostos 
híbridos definidos por Dick (1990a, p. 14) como "aquele designativo que recebe em sua configuração elementos linguísticos de diferentes procedências; a formação que se generalizou no país é a portuguesa + indígena ou a indígena + portuguesa: Lajinha do Mutum".

Ainda, o conceito engendrado sobre a estrutura formal do sintagma toponímico considera dois elementos formadores básicos:

Termo ou elemento genérico (relativo à entidade geográfica que irá receber a denominação - rio, córrego, serra, rua, bairro...); Elemento ou termo específico (ou o topônimo propriamente dito), que particularizará a noção espacial, identificando-a e singularizando-a dentre outras semelhantes - (rio) Dourados; (serra) de Maracaju; (rua) Eucalipto. (DICK, 1990a, p.10, grifos da autora)

Em relação à motivação toponímica, Dick (1990a) elaborou um modelo taxionômico que reúne os topônimos em duas grandes categorias que, por sua vez, reúnem um conjunto de taxes e/ou em taxionomias. Reunidos em dois grandes grupos, essas categorias estão assim dispostas: 1) Categorias de natureza física, que remetem a elementos naturais relacionados aos nomes de lugares (11 taxes): astrotopônimo, fitotopônimos, geomorfotopônimos, hidrotopônimos, zootopônimos, dentre outras; 2) Categorias de natureza antropocultural, relacionados à vida humana (16 taxes): animotopônimos ou nootopônimos; antropotopônimos; cronotopônimos; ergotopônimos; etnotopônimos; historiotopônimos; numerotopônimos; poliotopônimos; sociotopônimos; somatotopônimos, dentre outras.

Ainda é preciso considerar a estrutura do sintagma que distingue o acidente geográfico e o topônimo em questão; a título de exemplificação, transcrevemos, a seguir, o exemplo dado pela autora referida:

A categorização linguística de "pedra" inclui o termo no conjunto dos designativos ou nomes comuns, enquanto o sintagma toponímico morro de pedra - em que morro é o acidente geográfico de natureza física e pedra o topônimo propriamente dito - identifica um litotopônimo. (DICK, 1990a, p. 17, grifos da autora).

Discutidos os conceitos teóricos de base para o desenvolvimento e compreensão do estudo aqui proposto, no tópico seguinte apresenta-se o quadro metodológico que orientou as etapas de coleta e classificação dos topônimos do bairro Novos Estados. 


\section{Procedimentos metodológicos}

De acordo com os pressupostos teóricos apontados anteriormente, este trabalho fundamenta-se nos estudos do léxico, considerando a estreita relação entre língua, cultura e sociedade. Para tanto, buscou-se orientação teórica nos estudos sobre a Onomástica e literaturas específicas das áreas da Lexicologia e da Toponímia, sobretudo a teoria toponímica de Dick (1990a, 1990b), particularmente a obra A dinâmica dos nomes da cidade de São Paulo (DICK, 1996). Consideraram-se também parâmetros adotados pelo Projeto Atlas Toponímico do Estado de Mato Grosso do Sul (ATEMS), ao qual este estudo está vinculado.

Reiteramos que o estudo discute um recorte dos resultados do projeto de dissertação de Mestrado em desenvolvimento, intitulado "A toponímia urbana da cidade de Campo Grande: um estudo etnolinguístico dos nomes das ruas da região do Prosa" vinculado ao Programa de Pós-graduação Mestrado em Estudos de Linguagens - UFMS.

O corpus reuniu um total de 236 nomes de logradouros extraídos de folhas topográficas e mapas oficiais da prefeitura de Campo Grande - MS. Em primeira instância, consultou-se a SEMADUR (Secretaria Municipal do Meio Ambiente e Gestão Urbana) que gerencia o site do SIMGEO (Sistema Municipal de Geoprocessamento) cuja finalidade é desenvolver mecanismos de produção, gestão e compartilhamento de informações georreferenciadas para o planejamento, a execução e a avaliação de políticas locais. A título de apresentação, mostramos a seguir, na figura 1, a tela de abertura do site do SIMGEO.

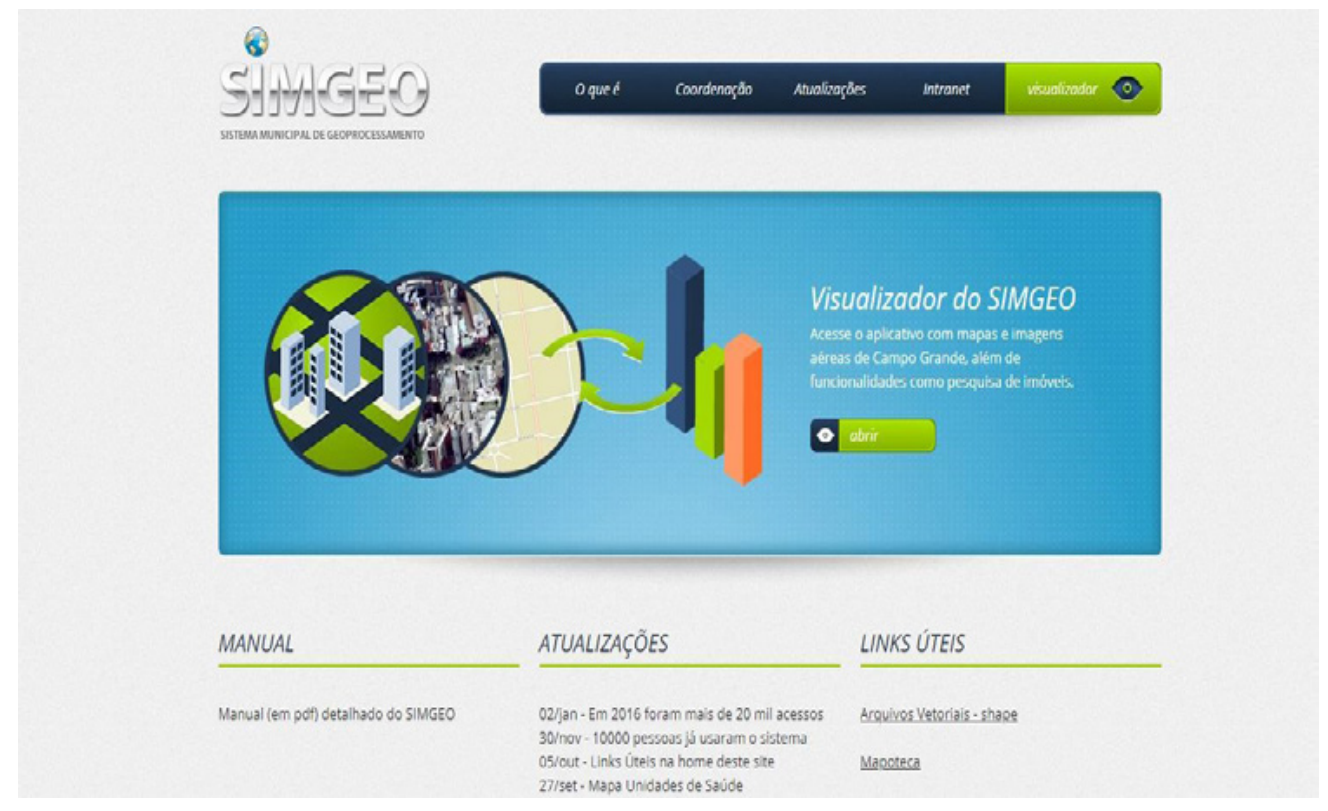

Figura 1. Tela de abertura do site SIMGEO 
Nesta página de abertura, no canto inferior direito, em links úteis, acessa-se o linkmapoteca que remete o usuário para a segunda tela na qual se tem acesso aos arquivos com os mapas oficiais separados por regiões urbanas, bairros e parcelamentos (subdivisões dentro do espaço delimitado para o próprio bairro), de Campo Grande - MS, disponíveis para download. Exemplificados, passo a passo, nas figuras de 2 - 4 abaixo.

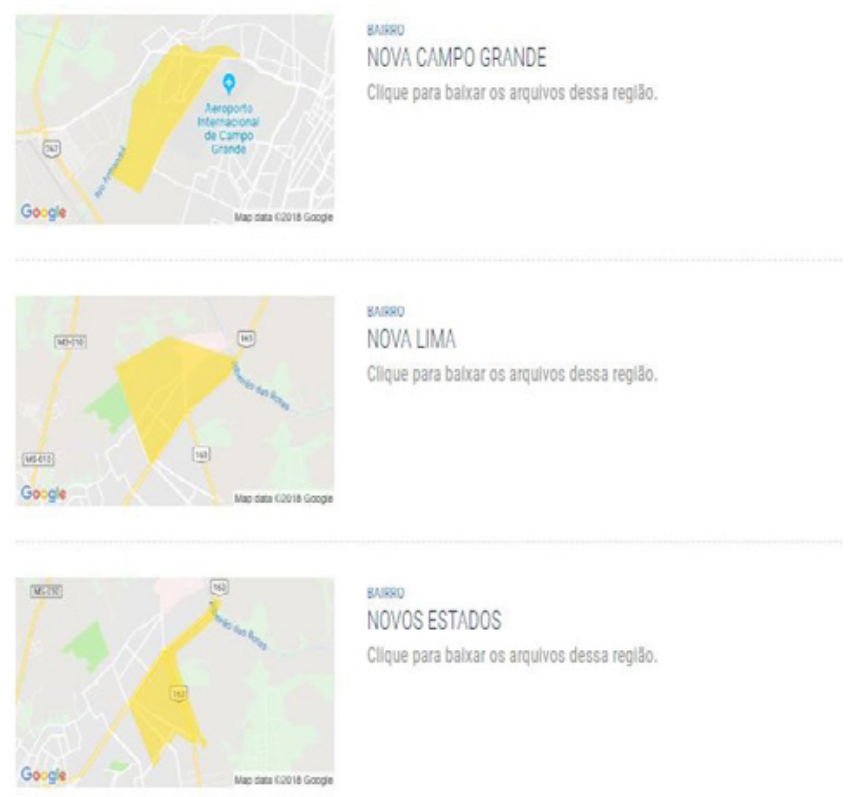

Figura 2. Telas de abertura do site do SIMGEO/Mapoteca

\section{ARQUIVOS PARA DOWNLOAD}

(2) novo amazonas - Conj. Res.

Novo Amazonas - Conj, Res.

(2) NOVO MaRAnhÄO-CONJ.RES

1 Novo Maranhăo - Conj.Res.

(1) NOVO MINAS GERAIS - CONJ.RES

Novo Minas Gerais - Conj. Res

1 NOVO parana - CONJ. RES

Novo Parana - Conj. Res.

(1) NOVO PERNAMBUCO-RES

NOVO PERNAMBUCO - RES

Figura 3. Tela de abertura do site do SIMGEO/Mapoteca-Download 


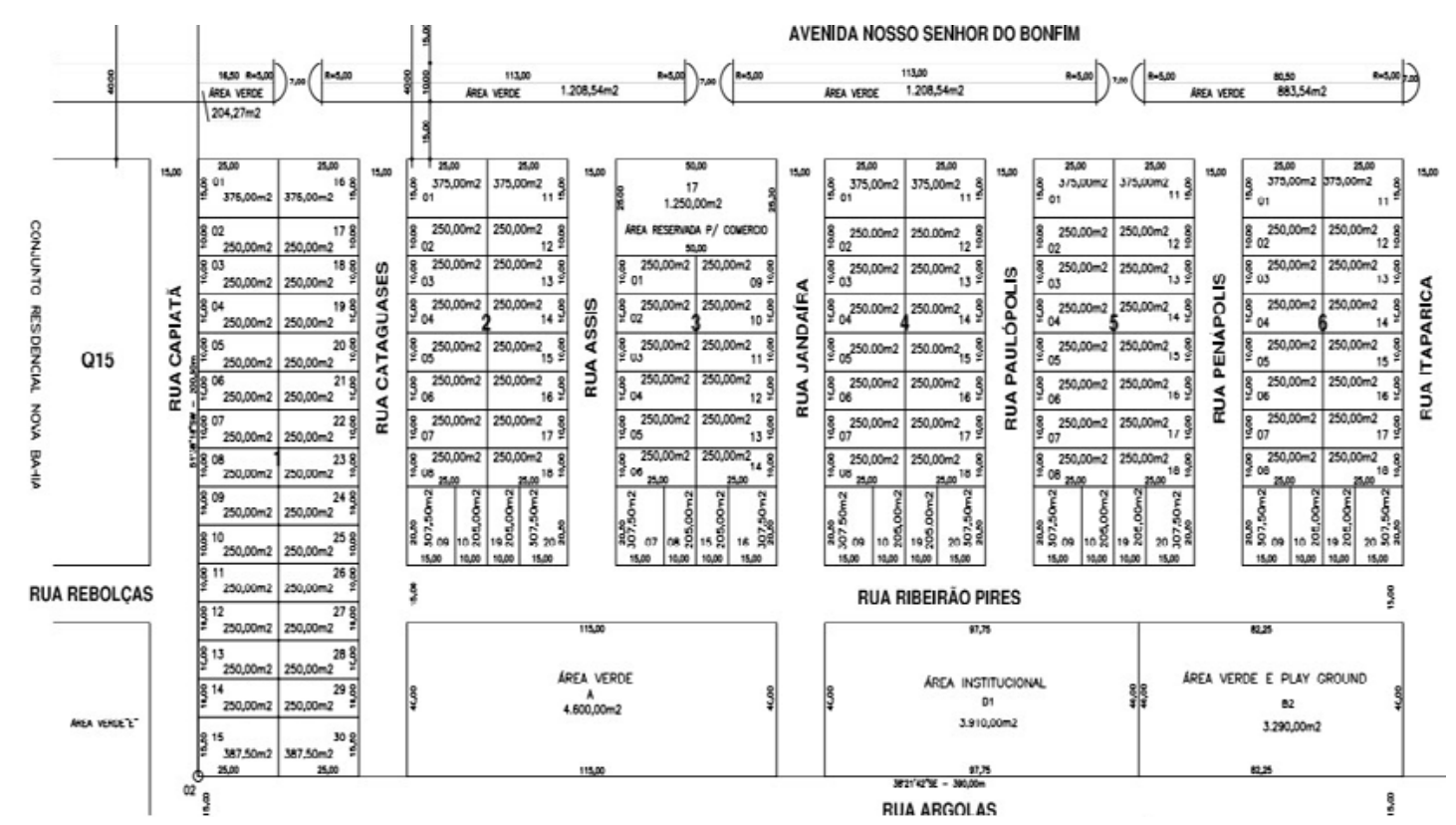

Figura 4. Tela de abertura do site do SIMGEO/mapoteca/bairro Novos Estados

A coleta dos topônimos dos mapas foi realizada manualmente. Após os nomes serem catalogados, na perspectiva dos estudos toponímicos, os dados recolhidos foram analisados sob os dois enfoques: aspectos linguísticos e extralinguísticos. Desta forma, buscou-se analisar as causas denominativas que motivaram o denominador no ato da nomeação que englobou a identificação da base linguística dos topônimos, a estrutura formal do sintagma toponímico e a classificação taxionômica, segundo o modelo taxionômico de Dick (1990a), conforme descrito no próximo tópico.

\section{Análise e resultados}

$\mathrm{Na}$ área pesquisada, constatou-se um montante de 236 topônimos, que correspondem a 17 taxes distintas. Dentre os dados catalogados, 86 nomes veiculam aspectos de natureza física que caracterizam determinado espaço em todos os aspectos que compõem sua formação, tais como, rios, córregos, dimensões, formações topográficas, árvores, animais etc. E, em uma proporção ainda maior, 92 designativos veiculam aspectos de natureza antropocultural, que caracterizam as manifestações psíquicas, sociais e culturais do homem, no meio em que este se encontra, o que inclui estado de ânimo, sentimentos, nomes próprios de pessoas, nomes de cidades, estados, países, títulos (DICK, 1990a). Há, ainda, 58 topônimos sem classificação por ausência de dados que justifiquem a motivação do designativo. 0 gráfico 1, a seguir, traz em percentuais esta primeira tendência identificada na toponímia urbana do bairro Novos Estados. 


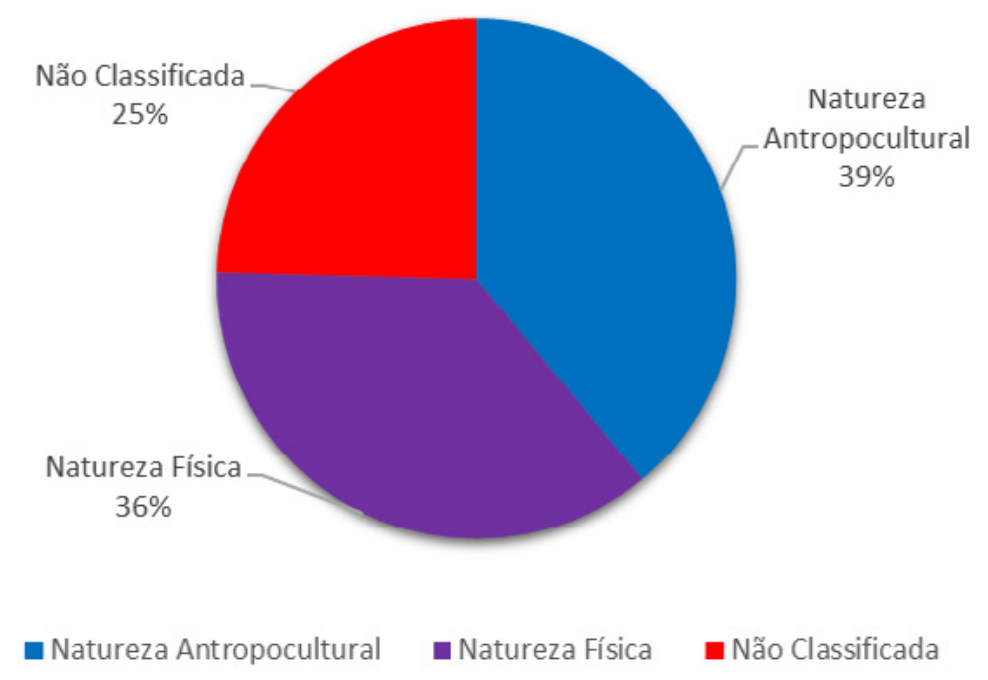

Gráfico 1. Natureza da motivação dos topônimos

Observa-se assim que, entre as duas categorias identificadas, 39\% dos designativos das ruas analisados tem sua motivação cunhada em aspectos de natureza antropocultural, enquanto 36\% dos nomes tem motivação em aspectos da natureza física.

Dentre as categorias de natureza antropocultural, as duas mais recorrentes no corpus em estudo foram: antropotopônimos (topônimos relativos aos nomes próprios individuais 37) e corotopônimos (topônimos relativos aos nomes de cidades, países, estados, regiões e continentes - 33). Estas tendências da toponímia analisada encontram respaldo nos estudos desenvolvidos por Dick (1990b). De fato, segundo a autora, os antropotopônimos compõem a categoria predominante na toponímia urbana:

\begin{abstract}
A conclusão que se pode retirar do estudo antroponímico na nomenclatura geográfica, em qualquer porção do território, certamente apontará a categoria estudada como a mais concorrida dentre as restantes. Cite-se, para ilustrar, o exame efetuado nas denominações municipais do Estado de São Paulo, que revelou cerca de 101 topônimos, dentre as áreas políticas, como pertencentes à taxeonomia antropotoponímica. (DICK, 1990b, p. 309)
\end{abstract}

No entanto, se por um lado os topônimos que representam nomes próprios de pessoas possuem respaldo teórico e legislativo para nomear ruas e logradouros, Lei 5.291 de 2014 (DIOGRANDE, 2014), por outro lado, os que designam nomes de cidades, países, estados e outros lugares geográficos não têm em sua motivação aspectos demasiados burocráticos. É o caso da segunda taxionomia mais recorrente apontada na categoria 
antropocultural, os corotopônimos. É neste sentido que Isquerdo (2012, p. 82), ao citar Dick (1990b), lembra-nos que os topônimos se configuram como "verdadeiros testemunhos históricos de fatos e ocorrências registrados nos mais diversos momentos da vida de uma população" (ISQUERDO, 2012, p. 82), isso porque, segundo a autora:

A história das palavras acompanha a saga histórica do homem, são transplantadas por ele e utilizadas para identificação de novos referentes, incluindo os lugares, até como uma forma de projeção, para outro espaço, do deixado para trás, isso explica a grande recorrência, em regiões de povoamento recente, de nomes transplantados precedidos do adjetivo 'novo', como Nova Europa, Nova Londrina, Nova Andradina, nomes que representam a tentativa de manutenção de um elo entre o passado e o presente. (ISQUERDO, 2012, p. 82).

Já no que se refere às categorias toponímicas de natureza física, as que se sobressaem são as seguintes: fitotopônimos (topônimos de índole vegetal - 53) e zootopônimos (topônimos de índole animal - 20). Essa terceira tendência pode ser justificada por influência da rica e diversificada flora e fauna do cerrado sul-matogrossense.

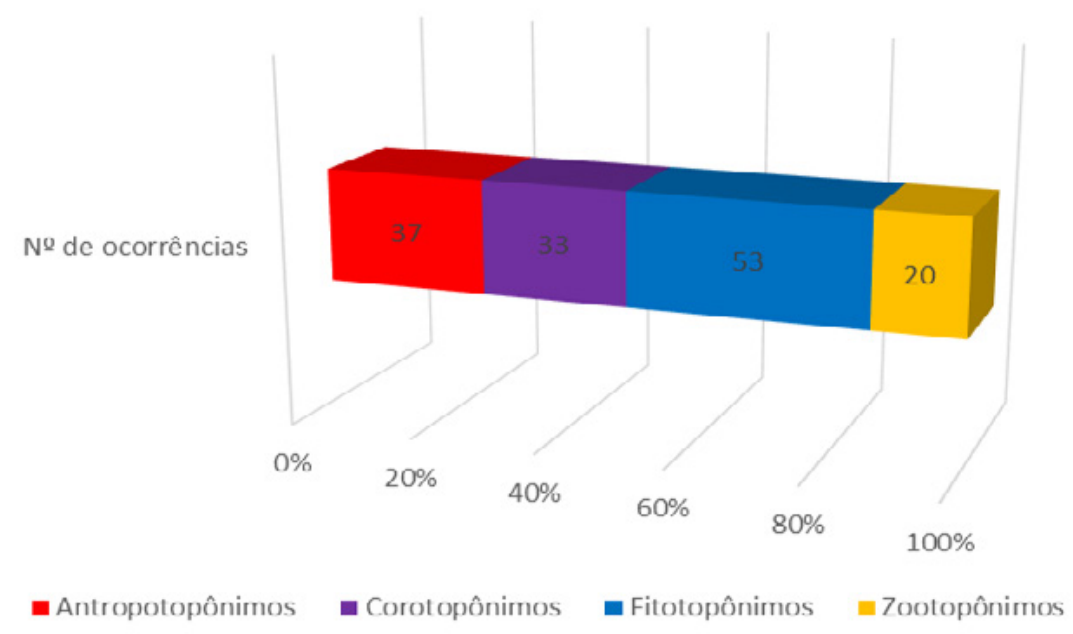

Gráfico 2. Taxionomias mais produtivas dos topônimos

Apresentamos, a seguir, uma amostra da análise de topônimos classificados com as taxionomias mais recorrentes no recorte de dados em análise, com destaque para suas respectivas causas denominativas. 
Quadro 1. Amostra de topônimos de natureza antropocultural e suas causas denominativas

Topônimo: Ada Teixeira dos Santos; Taxionomia: Antropotopônimo; Informações enciclopédicas: Ada Teixeira dos Santos, nascida em Campo Grande, no ano de 1916, formada na primeira turma da Escola Normal Joaquim Murtinho em 1934, atuou como professora primária no Grupo Escolar Joaquim Murtinho durante uma década e posteriormente passou a exercer o cargo de tabeliã do Cartório do $2^{\circ}$ Ofício em Campo Grande. A professora foi também sócia e fundadora da Associação Campo-Grandense de Professores - A.C.P. E. Dada sua importância, em sua homenagem, funciona atualmente na capital a Escola Estadual Professora Ada Teixeira dos Santos, e logradouro com seu nome. Disponível em: https://eeadateixeira.webnode.com. br/news/historia-da-escola-ada-teixeira/. Acesso em: 21 maio 2018.

Topônimo: Ayrton Senna da Silva; Taxionomia: Antropotopônimo; Informações enciclopédicas: Piloto brasileiro de Fórmula 1. Conquistou três vezes o campeonato mundial correndo pela McLaren. E, em 10 anos de Fórmula 1, disputou 116 corridas, conquistou 65 poles positions e ganhou 41 competições. Venceu por seis vezes o GP de Mônaco, e, por este motivo, o apelidaram por "O Rei de Mônaco". Disponível em: https://www.ebiografia.com/ayrton_senna/. Acesso em: 29 maio 2018.

Topônimo: Penápolis; Taxionomia: Corotopônimo; Informações enciclopédicas: Penápolis é um município localizado no estado de São Paulo. "Com o processo de interiorização da ocupação paulista, muitas famílias foram em busca de novas terras e oportunidades, trazendo o "progresso" à região. Em 22 de dezembro de 1.913, através da Lei Estadual no 1.397, foi criado o município de Penápolis, e em 10 de outubro de 1.917 pela Lei no 1.557, a Comarca de Penápolis, como uma das maiores da região. " (Prefeitura de Penápolis. História. Disponível em: https://www.penapolis.sp.gov.br/portal/cidade/1/Hist\%C3\%B3ria. Acesso em: 29 jun. 2018.

Topônimo: Ipatinga; Taxionomia: Corotopônimo; Informações enciclopédicas: Ipatinga é um município do estado de Minas Gerais, elevado a esta categoria pela Lei estadual $n^{\circ} 2764$, de 30-121962. De acordo com informações da biblioteca eletrônica do IBGE de Ipatinga - MG, "o topônimo Ipatinga é de origem indígena (tupi), e significa 'Pouso de Água Limpa'." (Ipatinga. Minas Geras. Histórico. Disponível em: https://biblioteca.ibge.gov.br/visualizacao/dtbs/ minasgerais/ipatinga.pdf. Acesso em: 29 jun. 2018. 
Quadro 2. Amostra de topônimos de natureza física e suas causas denominativas

Topônimo: Orquídea; Taxionomia: Fitotopônimo; Informações enciclopédicas: [Do lat. cient. Orchid- (v. orquidácea) + -ea.] Substantivo feminino.

1.Bot. Designação comum às plantas e flores da família das orquidáceas, impropriamente consideradas parasitas (FERREIRA, 2004)

Topônimo: Eucalipto; Taxionomia: Fitotopônimo; Informações enciclopédicas: Substantivo masculino. Bot. 1. Gênero de arbustos ou árvores de grande porte, da família das mirtáceas, de folhas coriáceas, lanceoladas, resinosas, flores pequenas e ger. grupadas em umbelas, e fruto que é uma cápsula com muitas sementes de testa escura, lisa e fina. Fornecem madeira de alburno delgado, claro, de cerne cuja cor vai do amarelo ao pardo, pardo-avermelhado, sendo mais ou menos pesada, e com depósitos de goma, e as folhas têm propriedades medicinais. Encerra cerca de 450 espécies. 2.Qualquer espécie desse gênero, como, p. ex., a Eucalyptus regnans, a árvore mais alta do mundo.

3.Qualquer espécime desse gênero. [Sin. ger.: eudésmia.] (FERREIRA, 2004)

Topônimo: Guanambi; Taxionomia: Zootopônimo; Informações enciclopédicas: [Var. de guainumbi.] Substantivo masculino. 1. Bras. Zool. V. beija-flor (FERREIRA, 2004)

Topônimo: Uirapuru; Taxionomia: Zootopônimo; Informações enciclopédicas: [Do tupi] Substantivo masculino. Bras. Zool. 1. Designação comum a várias espécies de aves passeriformes, piprídeas, especialmente as mais coloridas dos gêneros Pipra, Chiroxiphia, Teleonema. Seu canto, que só se ouve uns 15 dias por ano (quando constrói o ninho) e, ademais, apenas durante 5 a 10 minutos, ao amanhecer, é tido como particularmente melodioso, musical, e diverso do de outra ave qualquer, a ponto de, segundo a lenda, os outros pássaros todos se calarem para escutá-lo: "O uirapuru canta pra mim / e eu sou feliz só por poder ser, / só por ser de manhã" (Fátima Guedes, na canção Cheiro de Mato). [Var. e sin., em regiões diversas do Brasil: irapuru, guirapuru, arapuru, irapurá, tangará, rendeira, pássaro-de-fandango, realejo.] 2.V. uirapuru-verdadeiro. 3.Uiramiri. 4.V. rendeira² (2) (FERREIRA, 2004)

Como proposto inicialmente para este estudo, na sequência focaliza-se a questão das línguas identificadas nos topônimos do bairro Novo Estados/Campo Grande e a estrutura morfológica desses designativos.

Em relação às línguas de origens dos designativos, foram identificados nomes provenientes de seis idiomas distintos, sendo a maior parte dos topônimos 119 nomes de ruas, oriundos da língua portuguesa; em segundo lugar, se destacam, com 48 ocorrências, os nomes de línguas indígenas e, em terceiro, quarto e quinto lugar foram encontrados nomes de línguas, africanas, nomeando cinco ruas, espanhol e grego, ambas em nomes de três ruas, e árabe encontrada em apenas um designativo, como se pode observar os percentuais no gráfico seguinte: 


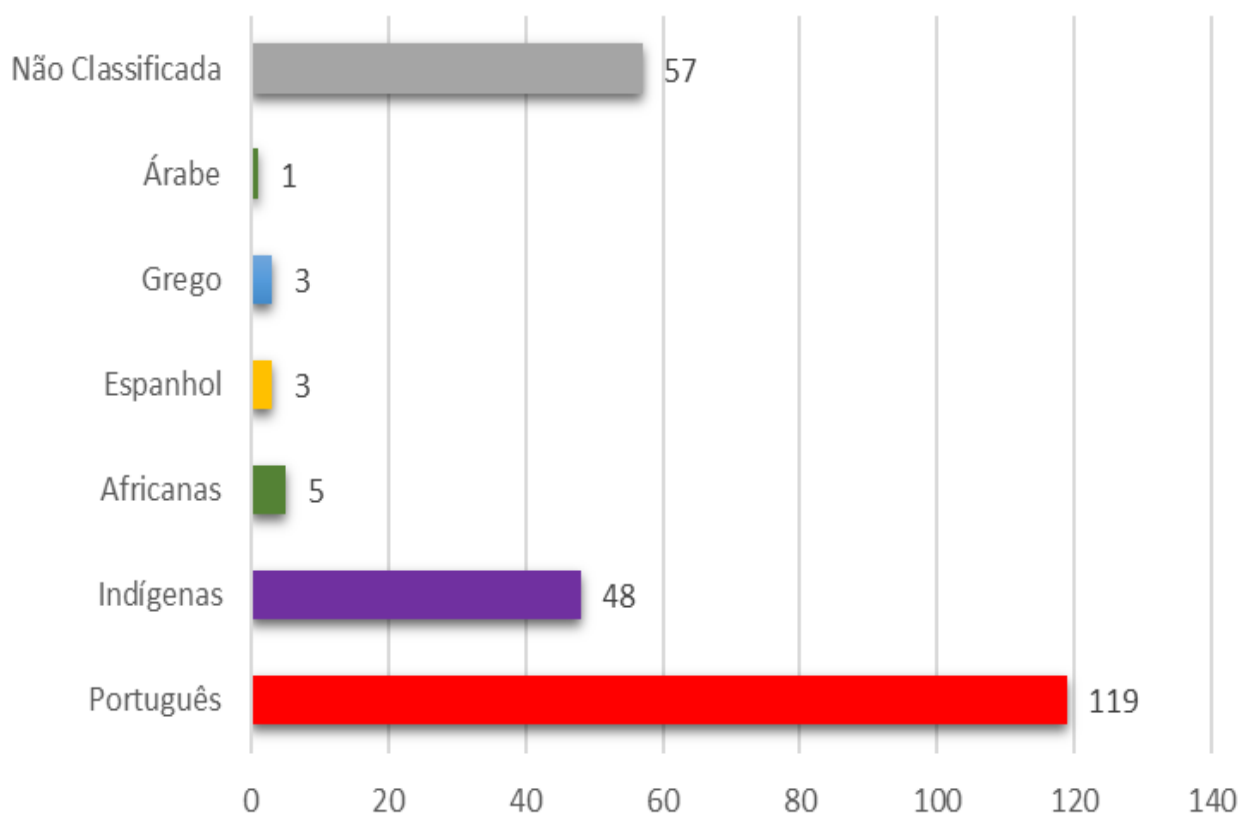

Gráfico 3. Distribuição dos topônimos segundo a língua de origem

Sabe-se que os contatos linguísticos ocorridos no Brasil colonial deram origem a uma sociedade híbrida, com características que a diferenciam da realidade portuguesa e que originou um modo particular de nomear essa realidade por meio do léxico que passou a ser característico do português do Brasil. Desta forma, justifica-se, a par das línguas portuguesa e indígena, as ocorrências de nomes oriundos de línguas africanas, haja vista que essa efervescência sociolinguística e cultural característica do Brasil é determinante da forma como a sociedade atual enxerga e organiza a realidade circundante por meio do léxico (OLIVEIRA, 1998).

Já no que se refere à estrutura formal dos topônimos, com máxima na escala, constatouse a presença de nomes cuja estrutura morfológica é de base simples (185 ocorrências - 78\%), seguidos de topônimos de base composta (50 ocorrências - 21\%) e de apenas um caso de topônimo com estrutura formal simples híbrida (1\%) como é o exemplo do topônimo encontrado para rua Pelourinho cujas bases são do francês pilori + poss. do lat. med. pillorium (FERREIRA, 2004). Abaixo se tem a demonstração gráfica dos dados apresentados. 


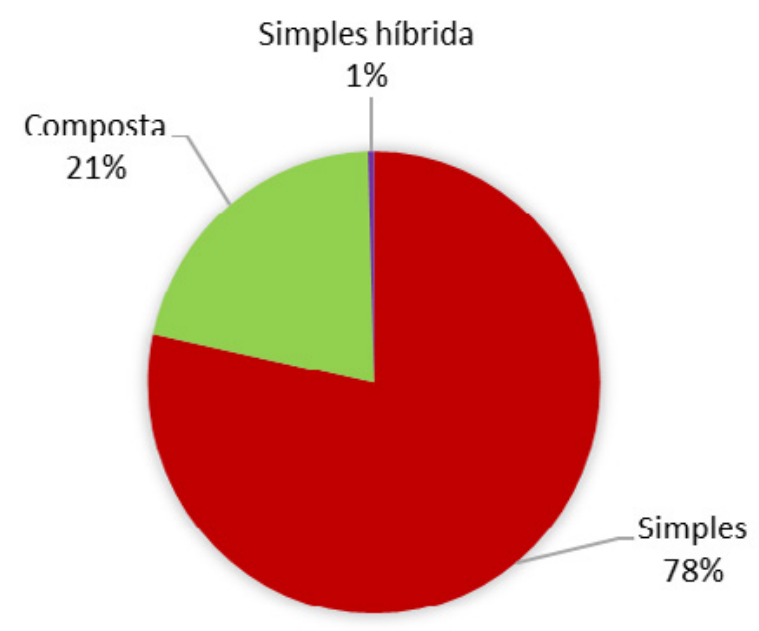

Gráfico 4. Estrutura morfológica dos topônimos

\section{Considerações finais}

Este artigo objetivou discutir dados preliminares da pesquisa de Mestrado em andamento cujo objeto de estudo é a toponímia urbana de Campo Grande, capital de Mato Grosso do Sul. A pesquisa demonstrou como principal tendência da toponímia urbana do bairro Novos Estados a presença de designativos de natureza antropocultural.

A expressiva presença de antropotopônimos resulta da homenagem prestada pelo nomeador (órgão público e/ou dono do loteamento que deu origem ao bairro), e recupera nomes de pessoas que se destacaram na história da cidade, preservando, assim, uma memória coletiva por meio da toponímia. Outro estudo acerca dessa categoria taxionômica foi desenvolvido por Amorim e Isquerdo (2017), cujos resultados obtidos podem contrastar aos desta pesquisa. As autoras catalogaram os topônimos de logradouros do bairro José Abrão, da cidade de Campo Grande/MS, com foco para os nomes próprios de pessoas. Ao todo foram encontrados 36 antropotopônimos que, de acordo com a análise por elas apresentada, prestam homenagem a personalidades de variadas profissões, por exemplo, poetas, pintores, escultores, arquitetos, geólogos, físicos e historiadores, cuja notoriedade nacional ou internacional foi conquistada a partir de seus feitos (AMORIM; ISQUERDO, 2017). De fato, "Os antropotopônimos são fontes de conhecimento tão excelentes quanto as melhores evidências documentais" (DICK, 1990a, p. 178).

Já a presença dos corotopônimos, que também compuseram o corpus deste trabalho, resulta da homenagem prestada aos migrantes que se deslocaram para Mato Grosso 
do Sul nas diferentes fases da formação da cidade, e que muito contribuíram com o desenvolvimento, a economia, a cultura que singularizam a capital Campo Grande - MS. As razões motivadoras por detrás dos designativos podem ser justificadas pela "saudade na toponímia" (DICK, 1990a, p. 203) que fixa por meio dos topônimos a "visualização imediata do detalhe histórico-cultural, que a memória do homem apaga, no decurso dos anos" (DICK, 1990a, p. 207).

Em relação às línguas de origens predominantes no recorte toponímico estudado, a língua portuguesa é a mais recorrente, seguida de línguas indígenas e africanas, respectivamente, que retrata uma característica da toponímia brasileira como um todo, devido à formação etno-histórica do Brasil, "origem heterogênea que deixou reflexos diferenciados na língua, nos usos e costumes, nas tradições regionais e, consequentemente, na toponímia do país" (DICK, 1990a, p. 81). Os dados morfológicos, no entanto, apareceram dispostos na seguinte sequência: predominou-se os nomes de estrutura simples, seguidos dos topônimos de estrutura composta e nomes híbridos, respectivamente.

Desta forma, reitera-se a importância do estudo da Toponímia urbana não só no âmbito das ciências do léxico, restringindo-se aos interesses de estudiosos da área, mas também da população como um todo, uma vez que, através dela, é possível compreender aspectos linguísticos, históricos, culturais, ideológicos e do ambiente físico, revelados através dos designativos de espaços urbanos.

\section{REFERÊNCIAS}

AGUILERA, V. A. Taxionomia de topônimos: problemas sem solução? Signum. Estudos Linguísticos, Londrina, v. 2, n. 1, p. 125-137, out. 1999.

AMORIM, B. S.; ISQUERDO, A. N. A antropotoponímia na nomeação dos logradouros do bairro José Abrão em Campo Grande (MS): alguns apontamentos. Revista Philologus, Rio de Janeiro, v. 23, p. 100-111, abr. 2017.

BIDERMAN, M. T. C. Terminologia e Lexicografia. Tradterm, São Paulo, v. 7, p. 153-181, dez. 2001. Disponível em: http://www.revistas.usp.br/tradterm/article/view/49147/53230. Acesso em: 27 ago. 2018.

DICK, M. V. P. A. Toponímia e Antroponímia no Brasil. Coletânea de Estudos. 2. ed. São Paulo: Serviços de Arte Gráfica da FFLCH/USP, 1990a.

DICK, M. V. P. A. A estrutura e as funções do signo toponímico. In: DICK, M. V. P. A. Toponímia e Antroponímia no Brasil. Coletânea de Estudos. 3. ed. São Paulo: Serviços de Arte Gráfica da FFLCH/USP, 1990a. p. 13-14. 
DICK, M. V. P. A. Aspectos genéricos da toponímia indígena brasileira e sua distribuição linguística. In: DICK, M. V. P. A. Toponímia e Antroponímia no Brasil. Coletânea de Estudos. 2. ed. São Paulo: Serviços de Arte Gráfica da FFLCH/USP, 1990a. p. 119-136.

DICK, M. V. P. A. Funções do topônimo. In: DICK, M. V. P. A. Toponímia e Antroponímia no Brasil. Coletânea de Estudos. 3. ed. São Paulo: Serviços de Arte Gráfica da FFLCH/USP, 1990a. p. 15-22.

DICK, M. V. P. A. O espontâneo e o popular na Toponímia. In: DICK, M. V. P. A. Toponímia e Antroponímia no Brasil. Coletânea de Estudos. 2. ed. São Paulo: Serviços de Arte Gráfica da FFLCH/USP, 1990a. p. 47-54.

DICK, M. V. P. A. A motivação toponímica e a realidade brasileira. São Paulo: Edições Arquivo do Estado de São Paulo, 1990b.

DICK, M. V. P. A. A nomeação toponímica e o "signo toponímico". In: DICK, M. V. P. A. A motivação toponímica e a realidade brasileira. São Paulo: Edições Arquivo do Estado de São Paulo, 1990b. p. 35-46.

DICK, M. V. P. A. Taxionomias de natureza antropocultural. In: DICK, M. V. P. A. A motivação toponímica e a realidade brasileira. São Paulo: Edições Arquivo do Estado de São Paulo, 1990b. p. 285-350.

DICK, M. V. P. A. A dinâmica dos nomes na cidade de São Paulo. 1554-1897. São Paulo: Annablume, 1996.

FERREIRA, A. B. de H. Novo dicionário Aurélio da Língua Portuguesa. Curitiba: Positivo, 2004. Versão digital 5.0.

HOUAISS, A. Dicionário Eletrônico Houaiss da Língua Portuguesa. Rio de Janeiro: Objetiva, 2001. Versão digital 1.0.

ISQUERDO, A. N. A motivação na toponímia: algumas reflexões. In: SELLA, A. F.; CORBARI, C. C.; BIDARRA, J. (org.). Pesquisas sobre léxico: reflexões teóricas e aplicação. Campinas: Pontes; Cascavel: Edunioste, 2012. p. 81-95.

OLIVEIRA, A. M. P. P. Brasileirismos e Regionalismos. Alfa, São Paulo, v. 42, n. esp., p. 109120, 1998. 
SEMADUR - Secretaria Municipal do Meio Ambiente e Gestão Urbana. Disponível em: http://www.campogrande.ms.gov.br/semadur. Acesso em: 25 abr. 2018.

SIMGEO. Sistema Municipal de Geoprocessamento. Disponível em: http://www. campogrande.ms.gov.br/simgeo/. Acesso em: 25 abr. 2018. 